\title{
PLACENTA PREVIA: MATERNAL AND FOETAL OUTCOME
}

Meenakshi Devarmani ${ }^{1}$, Patil Sanjana Tallur ${ }^{2}$

1 Professor, Department of Obstetrics and Gynaecology, M. R. Medical College, Gulbarga.

2Senior Resident, Department of Obstetrics and Gynaecology, M. R. Medical College, Gulbarga.

\section{ABSTRACT}

AIM

To analyse maternal and neonatal outcome in pregnancies complicated with placenta previa and to evaluate the potential risk factors.

\section{BACKGROUND AND OBJECTIVES}

To study the risk factors for placenta previa, to study the mode of deliveries, to study the maternal and foetal outcome and to study the incidence of placenta previa.

\section{METHODS}

50 pregnancies with placenta previa during a 2 years study period (2014-2016) were analysed. The total number of deliveries during the study period was 4759 . The data on the potential risk factors compiled; the information on the maternal and neonatal outcome was subjected to appropriate statistical analysis and following deductions provided.

\section{RESULT}

The incidence of placenta previa was $1.8 \%$. Factors significantly associated with development of placenta previa were advanced maternal age, number of previous caesarean section, number of previous abortions and multiparity. The complications seen most commonly in the neonatal outcome was prematurity at birth (42.85\%) followed by RDS (28.5\%) and aspiration (14.2\%); 48\% of the babies required resuscitation, out of which $24 \%$ required further NICU admission. The neonatal mortality calculated was $280 / 1000$ live births.

\section{CONCLUSION}

In the present study, the incidence of antepartum haemorrhage was $4.9 \%$ and placenta previa contributed to $37 \%$ of cases. The perinatal mortality due to placenta previa was 280 per 1000 live births. The maternal mortality rate due to placenta previa in this study is nil, but maternal morbidity was high, that is more than $60 \%$ of cases had antenatal, intranatal and postnatal complications and anaemia worsened the clinical state of patients.

\section{KEYWORDS}

Placenta Previa; Maternal Morbidity; Neonatal Mortality.

HOW TO CITE THIS ARTICLE: Devarmani M, Tallur PS. Placenta previa: maternal and foetal outcome. J. Evolution Med. Dent. Sci. 2016;5(40):2477-2480, DOI: 10.14260/jemds/2016/577

\section{INTRODUCTION}

Antepartum Haemorrhage (APH) still presents as one of the most dreaded and devastating group of disorder in obstetrics.

Vaginal bleeding in any stage of pregnancy is an alarming event generating significant concern in both patients and doctors and when occurring in third trimester causes are mainly placenta previa and abruptio placenta and marginal placental separation.

Majority of the painless vaginal bleeding in the 2' half of the pregnancy are associated with placenta previa, more common with neglected pregnancies, increased parity and advancing age.

Availability of blood for transfusion have dramatically decreased maternal mortality, morbidity and with better NICU facilities available, perinatal morbidity and mortality has

Financial or Other, Competing Interest: None.

Submission 16-03-2016, Peer Review 29-04-2016,

Acceptance 04-05-2016, Published 19-05-2016.

Corresponding Author:

Dr. Meenakshi Devarmani,

Professor,

Department of Obstetrics and Gynaecology,

M. R. Medical College, Sedam Road,

Gulbarga-585105, Karnataka, India.

E-mail: drssdevarmani@gmail.com

DOI: $10.14260 /$ jemds $/ 2016 / 577$ certainly been curtailed to a large extent; still, lot needs to be done in the lower socioeconomic group in urban slums and the rural India. Approximately $>40 \%$ patients deliver in hospitals without immediate 24 hours blood bank to facilities. These are the statistics and this is in booked cases, the state of unbooked case is even worse.

Placenta previa involves bleeding from placental site completely, which is located in the lower uterine segment either partially or completely and as the lower uterine segment stretches near term or in labour the associated bleeding is inevitable.

Antepartum haemorrhage forms one of the most dangerous and devastating group of disorders in obstetrics. Placenta previa contributes to 115 th of the cases of antepartum haemorrhage.

This catastrophic complication not only poses a risk to the foetus, but also endangers the mother's life. Developed countries have a near zero maternal mortality rate for placenta previa, but even with today's better medical facilities and awareness India lags way behind.

The maternal and neonatal outcome can be definitely improved in cases of placenta previa, as it can be diagnosed by antenatal USG even before the first episode of bleeding. Once the condition is diagnosed, the case should be judiciously managed and all steps required should be taken to treat the complications associated with such cases. These cases are to 
be managed only in centres where there are facilities for blood transfusion, immediate operative interventions and NICU facilities round the clock.

Better ANC and thorough screening of the patients with second trimester scan, better referral system, transport and more hospitals with 24 hours blood bank facility are the need of the labour.

All these measures can probably bring down the maternal and perinatal mortality and morbidity rates and achieve the standards of the developed countries.

\section{AIM OF THE STUDY}

1. To study the risk factors for placenta previa.

2. To study the mode of deliveries.

3. To study the maternal and foetal outcome.

4. To study the incidence of placenta previa.

\section{MATERIALS AND METHODS}

Analysis of maternal and neonatal outcome in cases of placenta previa occurring over a period of 2 years from Jan 2014 to Jan 2016. This study was carried out at the Basaveshwar Teaching and General Hospital, Gulbarga, attached to M. R. Medical College, Gulbarga.

\section{Inclusion Criteria}

Pregnant women with placenta previa confirmed by ultrasonography and with gestational age beyond 28 weeks were selected irrespective of their parity, type of placenta previa and with a live or dead foetus.

\section{RESULTS}

Out of 50 cases of placenta previa, 24 cases had minor degree of placenta previa and 26 cases had major degree of placenta previa; 41 cases were delivered by caesarean section; 38 as emergency as elective and 9 cases delivered vaginally.

\begin{tabular}{|c|c|c|c|c|}
\hline \multirow[b]{2}{*}{ Complications } & \multicolumn{2}{|c|}{ Percentage } & \multirow[b]{2}{*}{$\begin{array}{c}\text { Total } \\
(n=50)\end{array}$} & \multirow[b]{2}{*}{ Percentage } \\
\hline & $\begin{array}{l}\text { Minor } \\
(n=24)\end{array}$ & $\begin{array}{l}\text { Major } \\
(n=26)\end{array}$ & & \\
\hline $\begin{array}{c}\text { No. of episodes } \\
\text { of bleeding }\end{array}$ & 35 & 53 & 88 & - \\
\hline $\begin{array}{c}\text { Severe anaemia } \\
(<7 \mathrm{~g} \%)\end{array}$ & 6 & 10 & 16 & 32.00 \\
\hline Patients in shock & - & 8 & 8 & 16.00 \\
\hline $\begin{array}{c}\text { Antenatal blood } \\
\text { transfusions }\end{array}$ & 2 & 4 & 6 & 12.00 \\
\hline $\begin{array}{l}\text { Malpresentation- } \\
\text { breech }\end{array}$ & 3 & 4 & 7 & 14.00 \\
\hline IUD & 3 & 8 & 11 & 22.00 \\
\hline
\end{tabular}

\begin{tabular}{|c|c|c|c|c|}
\hline \multirow{2}{*}{$\begin{array}{c}\text { Intraoperative } \\
\text { Complications }\end{array}$} & $\begin{array}{c}\text { Type of Placenta } \\
\text { Previa }\end{array}$ & \multirow{2}{*}{ Total } & \multirow{2}{*}{ Percentage } \\
\cline { 2 - 5 }$(\mathbf{n = 2 4 )}$ & $\begin{array}{c}\text { Minor } \\
(\mathbf{n = 2 6 )}\end{array}$ & $\begin{array}{c}\text { Major } \\
\text { (n=50) }\end{array}$ & \\
\hline $\begin{array}{c}\text { Haemostatic } \\
\text { sutures Cho's }\end{array}$ & - & 2 & 2 & 4.00 \\
\hline $\begin{array}{c}\text { Vertical } \\
\text { haemostatic } \\
\text { sutures B-lynch }\end{array}$ & - & 1 & 1 & 2.00 \\
\hline \multicolumn{7}{|l}{ Table 2: Intraoperative Complications } \\
\hline
\end{tabular}

\begin{tabular}{|c|c|c|c|c|c|c|}
\hline \multirow{3}{*}{$\begin{array}{l}\text { Postoperative } \\
\text { Complications }\end{array}$} & \multicolumn{4}{|c|}{ Type of Placenta Previa } & \multirow{3}{*}{$\begin{array}{c}\text { Total } \\
(n=50)\end{array}$} & \multirow{3}{*}{ Percent } \\
\hline & \multicolumn{2}{|c|}{ Minor } & \multicolumn{2}{|c|}{ Major } & & \\
\hline & $\begin{array}{c}\text { Vaginal } \\
\text { (9) }\end{array}$ & $\begin{array}{l}\text { LSCS } \\
(15)\end{array}$ & $\begin{array}{c}\text { Vaginal } \\
(n=0)\end{array}$ & \begin{tabular}{|c|} 
LSCS \\
$(n=26)$
\end{tabular} & & \\
\hline Sepsis & - & - & - & 3 & 3 & 6.00 \\
\hline $\begin{array}{l}\text { Febrile } \\
\text { morbidity }\end{array}$ & - & 1 & - & 7 & 8 & 16.00 \\
\hline UTI & 1 & 1 & - & 6 & 8 & 16.00 \\
\hline PPH & - & 1 & - & 4 & 5 & 10.00 \\
\hline
\end{tabular}

\begin{tabular}{|c|c|c|c|c|c|c|}
\hline \multirow{8}{*}{ Outcomes } & \multicolumn{9}{|c|}{ Maturity and Mode of Delivery } & \multirow{2}{*}{ Table 4 } & \multirow{2}{*}{ Term(n=5) } & Preterm(n=45) & Total & Percent \\
\cline { 2 - 5 } & TSCS & Vaginal & LSCS & Vaginal & & \\
\hline Alive & 3 & 0 & 29 & 7 & 39 & 78 \\
\hline AUD & 1 & 1 & 8 & 1 & 11 & 22 \\
\hline \multicolumn{7}{|c|}{} \\
\hline
\end{tabular}

\begin{tabular}{|c|c|c|c|c|}
\hline Neonatal Outcome & Term & Preterm & Total & Percent \\
\hline $\begin{array}{l}\text { No. of neonates } \\
\text { requiring no } \\
\text { resuscitation }\end{array}$ & 3 & 23 & 26 & 52.00 \\
\hline NICU admissions & -- & 12 & 12 & 24.00 \\
\hline Expired within 48 hours & -- & 3 & 3 & 6.00 \\
\hline & & 9 & 9 & \\
\hline
\end{tabular}

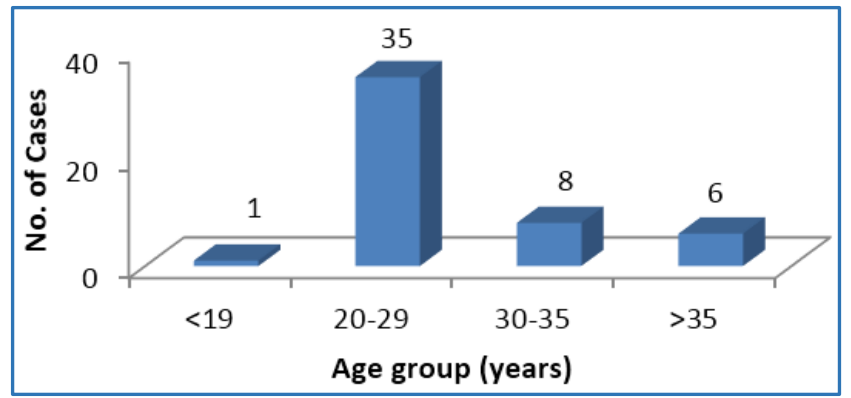

Graph Correlation of Maternal Age and Placenta Previa

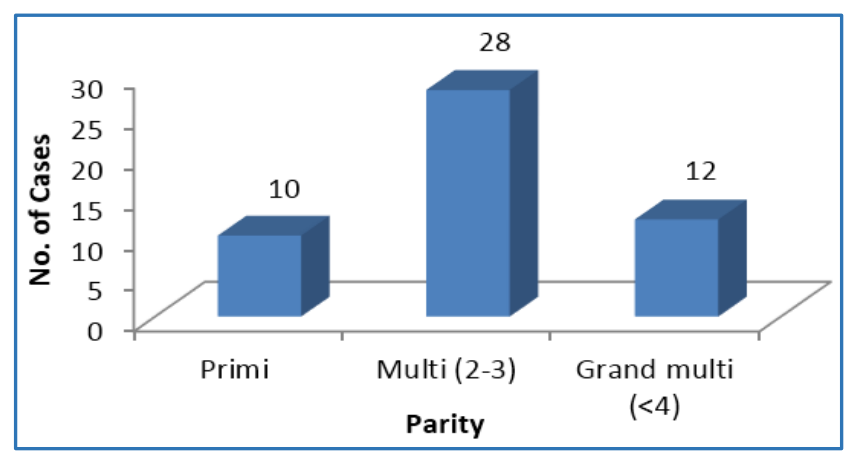

Graph Correlation of Parity and Placenta Previa

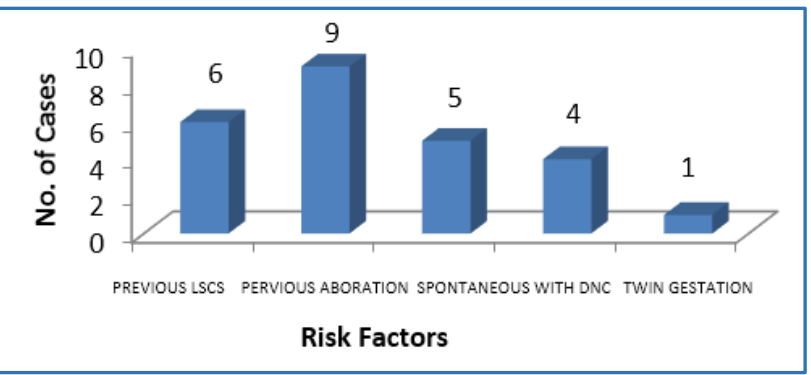

Graph Risk Factors for Placenta Previa 


\section{RESULT}

In the present study, analysis of maternal and neonatal outcomes in cases of placenta previa occurring over a period of 2 years from January 2014 to January 2016 at the Basaveshwar Teaching and General Hospital attached to M. R. Medical College, Gulbarga. We studied 50 eligible cases of placenta previa selected randomly. After detail analysis of the case, the present study was compared with other studies.

From the above study our incidence was almost similar to study conducted by Sharma BD. ${ }^{1}$ where the incidence of APH was $3.1 \%$ and placenta previa was $52.64 \%$, while in the present study the percentage of APH and placenta previa was $4.9 \%$ and $37 \%$ respectively. Our study shows that 50 eligible women among attending our hospital, only $30(60 \%)$ were booked while $20(40 \%)$ remained unbooked. Also the study conducted by Razial et $\mathrm{al}^{2}$ showed that the number of unbooked cases were (84\%). Similarly, our ANC care is also inadequate and a universal effort is required by all south Asian countries to improve the ANC and high risk screening for better outcome of maternal and neonatal welfare. The association between maternal age and incidence of placenta previa has been maximally in the age group 20 -29 years (56\%) about 28 cases in the present study.

This data correlates with the incidence seen in the same age group reported by Tariq. ${ }^{3}$ Michelle AW. ${ }^{4}$ and Steven Clark. ${ }^{5}$ In the present study 28 (56\%) multiparous women had placenta previa, while $12(24 \%)$ women were multigravida and $10(20 \%)$ women were primigravidae. These studies correlate with the statistic of studies done by Tariq. ${ }^{3}$ Michelle AW. ${ }^{4}$ and Steven Clark. ${ }^{5}$ Comparing our study with statistic of Victoria Taylor. ${ }^{6}$, our incidence of previous LSCS was $12 \%$ versus $20 \%$ and the percentage of previous spontaneous abortions in the present study was $18 \%$, whereas it was $36 \%$ in the study conducted by Victoria Taylor. ${ }^{6}$ The incidence of twin gestation in the present study is nearly double the incidence seen in the study done by Steven Clark. 5 , whereas incidence of twins were up to $6 \%$ in the study conducted by Savita Rani. ${ }^{7}$

The most common gestational age in our study group, which presented with bleeding was 30-34 weeks, whereas findings in Tariq. ${ }^{3}$ study showed maximum number of patients with first episodes of bleeding in 34-38 weeks group followed by 30-34 weeks. Our study show only $26 \%$ of women with normal haemoglobin, while $16 \%$ of patients had severe anaemia and transfusion was required in 29 (58\%) cases, whereas when compared with the study conducted by Tariq. ${ }^{3}$ only $16.7 \%$ of women were anaemic and blood transfusion given only in 3 women (3.5\%) who had their haemoglobin less than $9 \mathrm{gm} \%$. Our study is almost similar to the study conducted by P. Rani Reddy. ${ }^{8}$ study, where there were $20 \%$ of malpresentations.

Study conducted by McShane. ${ }^{9}$ showed $27 \%$ of malpresentations. When compared with the study done by McShane. ${ }^{9}$ our study has higher rates of sepsis, febrile illness, UTI and shock. This indicates that we must acquire a more appropriate and prompt approach in the management of placenta previa with good antibiotic coverage and better aseptic precaution. Resuscitation required for the neonates in the present study was $48 \%$, whereas in the study done by McShane. ${ }^{9}$ it was $33 \%$. NICU admissions in the present study done by McShane ${ }^{9}$ were $24 \%$ and $10 \%$ respectively, again indicating the inadequacy in our antenatal and perinatal care.
The mean Apgar score in the present study correlated with that of the McShane. ${ }^{9}$ study. Study conducted by Joan. ${ }^{10}$ had maximum perinatal mortality due to RDS, whereas prematurity was the most common cause of perinatal mortality in the present study. Perinatal mortality is very high in our study in all birth weight groups when compared to the study done by McShane. ${ }^{9}$

\section{DISCUSSION}

In the present study 50 cases of placenta previa were studied regarding the type of clinical presentation, the clinical course, the perinatal and maternal outcome. The information obtained was analysed statistically. In this study, it was observed that the incidence of APH was $4.9 \%$, out of the total number of deliveries and placenta previa contributed to $37 \%$ of cases of APH. In the present study, the cases of placenta previa were highest in the maternal age group of 20-29 years, i.e. $70 \%$. It was $16 \%$ in the age group of $30-35$ years, $12 \%$ in the age group $>35$ years and $2 \%$ in the present study was $25.96+4.7$ years. In the present study, incidence of placenta previa was highest (56\%) in the multiparous (2-3 viable births) group. It was $24 \%$ in the grand multi group ( $>4$ viable births) and 105 in the primi group. In the present study, the risk factors were caesarean section, abortion and twin gestation.

The incidence of prior caesarean section was $12 \%$, prior abortion was $18 \%$ and twin gestation in the present pregnancy was $2 \%$. Of the complications studied, in the present study severe anaemia $(<7 \mathrm{gm} \%)$ contributed to $32 \%$, malpresentation contributed to $14 \%$ and PIH was found in only $2 \%$ of cases. In the present study, $58 \%$ of cases required blood transfusion and shock/hypotension was noticed in $12 \%$ of cases, PPH was noticed in $10 \%$ of cases. In one case B-lynch was utilized to control intraoperative atonic PPH and in 2 cases Cho's multiple haemostatic sutures used for the bleeding from the placental site. Post-operative febrile morbidity was seen in $16 \%$ of the cases and sepsis complicated $6 \%$ of cases. In the present study, perinatal morbidity was studied as the percentage of babies requiring resuscitation and NICU admission. It was $48 \%$ and $24 \%$ respectively.

In the present study, the percentage of perinatal deaths was $28 \%$. Prematurity was the major contributor to perinatal deaths, i.e. $42.85 \%$ followed by RDS $28.5 \%$ and aspiration contributed to $14.2 \%$ each. The perinatal mortality was the same in both the clinical types of placenta previa, i.e. chi square value was 1.26 which is not significant. The perinatal mortality was more in the 28-33 weeks gestation group i.e. 51\%, whereas in the 34-36 weeks and 37+ weeks gestation group it was $34.28 \%$ and $14.28 \%$. Infants with birth weights above 2500 grams had a good survival rate and infants with birth weight $<1000$ grams had a very poor survival rate.

\section{CONCLUSION}

In the present study, the incidence of antepartum haemorrhage was $4.9 \%$ and placenta previa contributed to $37 \%$ of cases. The general perinatal mortality was 81 per 1000 live births and that due to placenta previa was 280 per 1000 live births, i.e. approximately 4 times higher than the general perinatal mortality rate. The maternal mortality rate due to placenta previa in this study was nil, but maternal morbidity was high, i.e. more than $60 \%$ of cases had antenatal, intranatal and/or postnatal complications and anaemia worsened the clinical state of the patients. 
As the maternal and perinatal morbidity and mortality due to placenta previa is preventable, efforts should be made to bring down these rates. This can be achieved by better spacing in between pregnancies, limitation of family size, antenatal registration of all pregnant women, routine use of USG in pregnancy and early referral of high risk pregnant women to tertiary care centres. Awareness should be brought about in the urban slums and rural public to avail the facilities provided by the government.

These measures will definitely help in a better outcome for both mother and foetus in all high-risk pregnancies.

\section{REFERENCES}

1. Sharma A, Gupta I, Suri V. Tocolytic therapy in conservative management of symptomatic placenta previa. Intl J of Obstet \& Gynaecol 2004;84(2):109-13.

2. Razia Mehboob, Nazir Ahmed. Maternal and fetal outcome in placenta previa. Pakistan J Med Res 2003;42(1).

3. Tariq khasbhoggi, Arab Board. Correlation of placenta previa with maternal and neonat outcome. Ann Saudi Med 1995;15(4).
4. Michelle A Williams, Mittendorf R. Increasing maternal age as a determinant of placenta previa more important than increasing parity? J of Rep Med 1993;38(6):425-8.

5. Steven Clark, Koonings PP, Phelan JP. Placenta previa/ accreta and prior caesarean section. Obstet Gynaecol 1985;66(1):89-92.

6. Victoria Taylor, Kramer MD, Vaughan TL, et al. Placenta previa and prior caesarean delivery: how strong is the association. Obstet Gynaecol 1994;84(1):55-7.

7. Savita Rani, Singhal, Nymphaea, et al. Maternal and perinatal outcome in APH. Intl J Obstet and Gynaecol 2008;9(2).

8. Reddi P Rani. Placenta previa- an analysis of 4 year experience. Indian J of Obstet Gynaecol 1999;19(3):586-8.

9. McShane PM, Heyl PS, Epstein MF. Maternal and perinatal morbidity resulting from placenta previ. J Obstet and Gynaecol 1985;65(2):176-82.

10. Joan MG, Crane Michel C, Van D, et al. Neonatal outcome in placenta previa. Am J Obstet and Gynaecol 2001;97(1):358. 